\title{
PICK1 Targets Activated Protein Kinase C $\alpha$ to AMPA Receptor Clusters in Spines of Hippocampal Neurons and Reduces Surface Levels of the AMPA-Type Glutamate Receptor Subunit 2
}

\author{
Jose L. Perez, Latika Khatri, Craig Chang, Sapna Srivastava, Pavel Osten, and Edward B. Ziff \\ Howard Hughes Medical Institute, Department of Biochemistry, New York University School of Medicine, New York, \\ New York 10016
}

The PICK1 protein interacts in neurons with the AMPA-type glutamate receptor subunit 2 (GluR2) and with several other membrane receptors via its single PDZ domain. We show that PICK1 also binds in neurons and in heterologous cells to protein kinase $\mathrm{C} \alpha(\mathrm{PKC} \alpha)$ and that the interaction is highly dependent on the activation of the kinase. The formation of PICK1$\mathrm{PKC} \alpha$ complexes is strongly induced by TPA, and PICK1-PKC $\alpha$ complexes are cotargeted with PICK1-GluR2 complexes to spines, where GluR2 is found to be phosphorylated by PKC on serine 880 . PICK1 also reduces the plasma membrane levels of the GluR2 subunit, consistent with a targeting function of PICK1 and a PKC-facilitated release of GluR2 from the synaptic anchoring proteins ABP and GRIP. This work indicates that PICK1 functions as a targeting and transport protein that directs the activated form of PKC $\alpha$ to GluR2 in spines, leading to the activity-dependent release of GluR2 from synaptic anchor proteins and the PICK1-dependent transport of GluR2 from the synaptic membrane.

Key words: GluR2; PKC $\alpha$; PICK1; PDZ domain; spine; endocytosis
Recent studies indicate that the strength of excitatory transmission can undergo long-lasting modification that is dependent on changes in AMPA receptor synaptic abundance (for review, see Luscher et al., 2000; Malinow et al., 2000). AMPA receptors are tetrameric (or pentameric) complexes, consisting of four subunit types [AMPA-type glutamate receptor subunits 1-4 (GluR1-4), also called GluR A-D (Seeburg, 1993)] (for review, see Hollmann and Heinemann, 1994). Receptor subunit cytoplasmic C termini may associate with synaptic scaffolding and regulatory proteins via PDZ domains (for review, see Ziff, 1997). Two multi-PDZ proteins that bind to the GluR2 $\mathrm{C}$ terminus, the GRIP and ABP proteins, are localized with GluR2 at synapses (Srivastava et al., 1998; Burette et al., 2001). Because a peptide containing the GluR2 PDZ binding motif disperses GluR2 clusters (Dong et al., 1997), PDZ proteins are likely to contribute to AMPA receptor clustering or synaptic localization. Indeed, mutations of the GluR2 PDZ binding site that selectively block GluR2 binding to ABP and GRIP accelerate GluR2 endocytosis at synapses (Osten et al., 2000). These findings identify ABP and GRIP as anchors that contribute to AMPA receptor synaptic abundance. Phosphorylation of GluR2 by protein kinase C (PKC) at serine 880 (S880) within the PDZ binding region prevents the association of

\footnotetext{
Received March 7, 2001; revised April 25, 2001; accepted May 9, 2001.

S.S. was supported by National Institutes of Health Grant AG13620 (to E.B.Z.). J.P. and P.O. were Associates and E.B.Z. is an Investigator of the Howard Hughes Medical Institute. We thank M. Barry, I. Greger, and J. Hanley for a critical reading of this manuscript; R. Abagyan for assistance with molecular modeling; and T. Serra for help in the preparation of this manuscript.

Correspondence should be addressed to Edward B. Ziff, Howard Hughes Medical Institute, Department of Biochemistry, New York University School of Medicine, New York, NY 10016. E-mail: edward.ziff@med.nyu.edu.

J. Perez's present address: Sugen, Incorporated, 230 East Grand Avenue, South San Francisco, CA 94080.

S. Srivastava's present address: J. P. Morgan Securities Incorporated, 60 Wall Street, New York, NY 10260.

P. Osten's present address: Max Planck Institute for Medical Research, Department of Molecular Neurobiology, Jahnstrasse 29, 69120 Heidelberg, Germany.

Copyright (C) 2001 Society for Neuroscience 0270-6474/01/215417-12\$15.00/0
}

GluR2 with ABP and GRIP (Matsuda et al., 1999, 2000; Chung et al., 2000). S880 phosphorylation therefore may contribute to the release of GluR2 from synaptic membrane anchors, leading to endocytosis.

The PICK1 protein was identified in a yeast two-hybrid screen by its ability to bind via its single PDZ domain to the catalytic domain fragment of PKC $\alpha$ (Staudinger et al., 1995, 1997). PICK1 binds in vivo to a variety of transmembrane proteins, including the GluR2 AMPA receptor subunit, the eph receptor tyrosine kinases, and ephrin ligands, and to mGluR7 and class I ADP ribosylation factors (Torres et al., 1998; Dev et al., 1999, 2000; Xia et al., 1999; Boudin et al., 2000; El Far et al., 2000; Takeya et al., 2000). Dev et al. (2000) have isolated complexes containing PKC $\alpha$, PICK1, and mGluR7, suggesting that PICK1 can interact with the full-length PKC $\alpha$ enzyme. However, the conditions that are necessary for PICK1-PKC $\alpha$ association have not been established. Furthermore, the PDZ binding sites at the $\mathrm{C}$ termini of PKC $\alpha$ and GluR2 display different structural motifs, and no PDZ domain aside from that of PICK1 has been reported to bind both types of motifs.

We have analyzed the function of PICK1 in hippocampal neurons and heterologous cells. We demonstrate that PICK1 binding to $\mathrm{PKC} \alpha$ requires $\mathrm{PKC} \alpha$ activation, whereas the interaction with GluR2 is constitutive. Formation of a PICK1 complex concentrates activated PKC $\alpha$ in spines where it may phosphorylate GluR2. It also reduces the level of GluR2 in the synaptic plasma membrane. Thus, the present work suggests that PICK1 has a role in the release of GluR2 from synaptic anchors and in receptor transport from the synaptic membrane.

\section{MATERIALS AND METHODS}

Yeast two-hybrid system. The yeast two-hybrid screen was performed with the CG-1945 yeast strain. GluR2 C-terminal DNA fragment (GluR2 834-883) was subcloned in the DNA binding domain vector pAS2. A rat brain cDNA library, constructed in the GAL4 activation domain vector pGAD10, was screened by using the Matchmaker Two-Hybrid System 
(Clontech, Palo Alto, CA). Six positive clones (as assayed by $\beta$-gal staining) encoding PICK1 were obtained. The sequenced PICK1 clones started at -50 of the murine PICK1 mRNA coding sequence. Yeastmating assays were performed with two yeast strains, CG-1945 and Y187. To verify the specificity of the GluR2-PICK1 interaction, we mated the CG-1945 yeast strain that was transformed with a PICK1 clone in the pGAD10 vector with the Y187 yeast strain that was transformed with control vectors: empty pAS2 vector, p53 subcloned in pAS2, and Myc subcloned in pAS2. For the GluR2 C-terminal domain analysis and the analysis of GluR subunit specificity, different regions of the GluR2 C terminus and the GluR1, GluR3, and GluR4 C termini were subcloned in the pAS2 vector.

Antibodies. Anti-FLAG monoclonal antibodies and tissue plasminogen activator (TPA) were purchased from Sigma (St. Louis, MO).

Anti-PICK1 polyclonal serum was generated by a synthetic peptide corresponding to the last 15 terminal amino acid residues in PICK. Antibodies were generated and purified by AnaSpec (San Jose, CA). Anti-PKC $\alpha$ polyclonal and monoclonal antibodies were purchased from Chemicon (Temecula, CA) and Transduction Laboratories (Lexington, KY), respectively. Polyclonal anti-GluR2/3 and monoclonal anti-GluR2 serum was purchased from Chemicon. Anti-phospho-GluR2 polyclonal serum was generated by using a synthetic phosphopeptide corresponding to 12 terminal amino acids in GluR2 [H]-C-Y-N-V-G-I-E Pser-V-K-I$[\mathrm{OH}]$. Antibodies were generated and affinity purified by Covance (Princeton, NJ).

Plasmids. The coding sequence of PICK1 was amplified from the GAD clone that was identified from the yeast two-hybrid screen by the primers 5"-TATATATAGAATTCGCCGCCACCATGTTTGCAGACTTAGA-3 and 5'-TATATATCTAGACTACTTGTCGTCCTTGTAGTCTTCAATACAGGCCCA-3'. The upstream primer included an EcoRI site as well as a Kozak consensus sequence and translational start site. The downstream primers added the FLAG epitope and a $\mathrm{XbaI}$ site to the coding sequence for the C-terminal end of PICK1. PICK1 $\Delta 121$ was constructed with primers that introduced a translational start site at position 121 of PICK. The products were digested with EcoRI and $X b a \mathrm{I}$ and then cloned into the respective sites in pcDNA 3.0, resulting in pcPICK and pc $\Delta 121$ PICK. Alanine was introduced into positions 27 and 28 via PCR. The amplified fragment was digested with BstEII and ligated into the $B s t$ EII site of pcPICK1, resulting in pcPICK1KD27,28AA. The C-

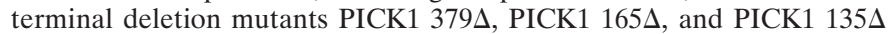
were generated via PCR with primers $5^{\prime}$-TATATATAGAATTCGCCGCCACCATGTTT GCAGACTTAGA-3' and $379 \Delta$ (5'-TATATATCTAGACTACTTGTCCTTGTAGTC AGTGAAGCTGCC-3'), $165 \Delta$ (5'-TATATATCTAGACTACTTGTCCTTGTAGTC CCCTTTGTACAG-3'), and $135 \Delta$ (5'-TATATATCTAGACTACTTGTCCTTGTAGTC ATCAGCTGTGCC-3'). The downstream primers introduced the FLAG epitope at the C-terminal ends of the mutants. The alanine substitutions in pcPICK1KD27,28AA were inserted by PCR, and the coding sequences of pcPICK and the mutant PICK1 plasmids were verified by sequencing. Glutathione $S$-transferase-R2C (GST-R2C) was constructed as described previously (Srivastava et al., 1998).

In vitro translation and GST pulldowns. pcPICK1 was translated in vitro, using the Master Mix in vitro translation system. Proteins were labeled by the addition of $\left[{ }^{35} \mathrm{~S}\right]$ methionine to the translation mix.

Labeled proteins were added to GST-R2C that was bound to glutathione-agarose in $1 \mathrm{ml}$ of $1 \%$ Triton $\mathrm{X}-100$ lysis buffer. The GST pulldowns were rocked for $2 \mathrm{hr}$ at $4^{\circ} \mathrm{C}$. Then the immobilized proteins were washed three times with lysis buffer and fractionated by SDSPAGE. The gel was fixed and incubated with Enhance, dried, and subjected to autoradiography.

Transfection, TPA stimulation, and coimmunoprecipitation. Plasmids expressing wild-type PICK and mutant PICK, PKC $\alpha$, and GluR2 were introduced into $293 \mathrm{~T}$ cells by calcium phosphate transfection. Transfected cells were washed, refed with media containing $10 \%$ fetal bovine serum, and harvested $72 \mathrm{hr}$ after transfection by being scraped into $1 \mathrm{ml}$ of PBS and centrifuged. Cell pellets were lysed in $1 \mathrm{ml}$ of Tris, Triton, glycerol buffer (TTG) and clarified by centrifugation. The cell lysates were incubated with antibodies at $4^{\circ} \mathrm{C}$ for $2 \mathrm{hr}$. Immune complexes were collected by binding to protein A-agarose by rocking at $4^{\circ} \mathrm{C}$ and washing three times with lysis buffer. Immunoprecipitated proteins were fractionated by SDS-PAGE, transferred to nitrocellulose, and subjected to Western blot analysis. To activate PKC $\alpha$, we treated transfected cells with TPA $(100 \mathrm{ng} / \mathrm{ml})$ for $30 \mathrm{~min}$ at $37^{\circ} \mathrm{C}$.

Immunocytochemistry. NIH 3T3 cells were grown on coverslips and transfected as described above. Cells were fed $18 \mathrm{hr}$ after transfection.
Then the transfected cultures were fixed in $4 \%$ paraformaldehyde $48 \mathrm{hr}$ after transfection. The fixed cells were permeabilized with $0.25 \%$ Triton $\mathrm{X}-100$ and incubated with primary sera in a humidified chamber for $18 \mathrm{hr}$ at $4^{\circ} \mathrm{C}$. Coverslips were washed three times in PBS and then incubated with FITC-conjugated donkey anti-rabbit anti-rhodamine-conjugated anti-mouse antibodies for $1 \mathrm{hr}$. Coverslips were washed and mounted onto slides. Proteins were visualized by immunofluorescence, using a Nikon PCM 2000 personal confocal microscope. To activate PKC $\alpha$, we treated transfected cells on coverslips with TPA as described above.

Neuron culture, infection, and immunostaining. Briefly, hippocampal primary cultures were prepared from embryonic day 18 (E18) Sprague Dawley rat embryonic tissue by dissociation with trypsin, were plated in serum containing MEM medium on poly-L-lysine-coated coverslips at a density of 80,000 per well of a six-well Falcon plate $\left(8400 / \mathrm{cm}^{2}\right)$, and were maintained in Neurobasal medium with B27 (NB-B27; Life Technologies, Gaithersburg, MD). To prepare Sindbis virus PICK1 vectors, we electroporated baby hamster kidney (BHK) cells with RNA for pSinRep5-PICK1 or the PICK1 mutants and the helper DH(265) according to the Sindbis expression system manual (Invitrogen, San Diego, CA). Preparation of MycR2 vectors was described previously (Osten et al., 2000). Expression from Sindbis virus vectors and the detection of MycR2 or PICK1 peptides in neurons were performed as described previously (Osten et al., 2000).

In vitro phosphorylation. GST-R2C or GST-R2CS880A $(1 \mu \mathrm{M})$ was incubated in buffer containing (in mM) 20 HEPES, pH 7.4, $1 \mathrm{MgCl}_{2}$, and 1 ATP plus protease inhibitors and $10 \mathrm{~nm}$ protein kinase $\mathrm{C}$ catalytic subunit (Calbiochem, La Jolla, CA) at $30^{\circ} \mathrm{C}$ for $30 \mathrm{~min}$. Proteins were fractionated by SDS-PAGE, transferred to nitrocellulose, and subjected to Western blot analysis.

\section{RESULTS}

In the course of a yeast two-hybrid screen of a rat brain cDNA library that used the 50 amino acid C-terminal domain of GluR2 as bait (Osten et al., 1998; Srivastava et al., 1998), we isolated positive-interacting clones expressing the PICK1 protein (Fig. $1 A$ ), as was reported previously by others (Dev et al., 1999; Xia et al., 1999). Binding of PICK1 to GluR2 induces perinuclear clusters of GluR2 in heterologous cells and synaptic clusters in neurons (Dev et al., 1999; Xia et al., 1999). We also saw redistribution when GluR2 and PICK1 were coexpressed in 3T3 cells (Fig. 1B). The catalytic domain fragment of $\mathrm{PKC} \alpha$ binds to PICK1 in the yeast two-hybrid assay (Staudinger et al., 1995, 1997). PICK1, PKC $\alpha$, and mGluR7 also form a complex in neurons (Dev et al., 2000). However, the capacity of PICK1 and PKC $\alpha$ to interact directly and the mechanisms that may control this interaction have not been examined. We therefore examined the patterns of PKC and PICK1 in 3T3 cells for similar redistribution as evidence of protein interaction. In $3 \mathrm{~T} 3$ cells expressing PKC $\alpha$ by transfection, the kinase displayed a diffuse pattern (Fig. $1 C)$ that was not affected by the coexpression of exogenous PICK1 (Fig. 1D). Because the catalytic fragment of PKC, but not the full-length enzyme, associated with PICK1 in the yeast twohybrid assay (Staudinger et al., 1997), we hypothesized that steric factors might influence the interaction. In the absence of stimulatory signals, $\mathrm{PKC} \alpha$ assumes an inactive conformation in which a pseudosubstrate sequence in the $\mathrm{N}$-terminal regulatory domain occupies the active site in the C-terminal catalytic domain (Newton, 1997). In this conformation the PDZ interaction motif at the $\mathrm{C}$ terminus potentially could be concealed. Binding of diacylglycerol and $\mathrm{Ca}^{2+}$ to the N-terminal regulatory domain of $\mathrm{PKC} \alpha$ induces a conformational change that releases $\operatorname{PKC} \alpha$ from the inhibition by removing the pseudosubstrate sequence from the C-terminal catalytic domain (Orr et al., 1992). Phorbol esters induce a similar PKC $\alpha$ rearrangement. To determine whether the PKC $\alpha$ conformational change that accompanies activation enables PKC $\alpha$ to bind to PICK1 by unmasking the $\mathrm{C}$ terminus, we assayed the effect of TPA treatment on the distribution of PKC 
A
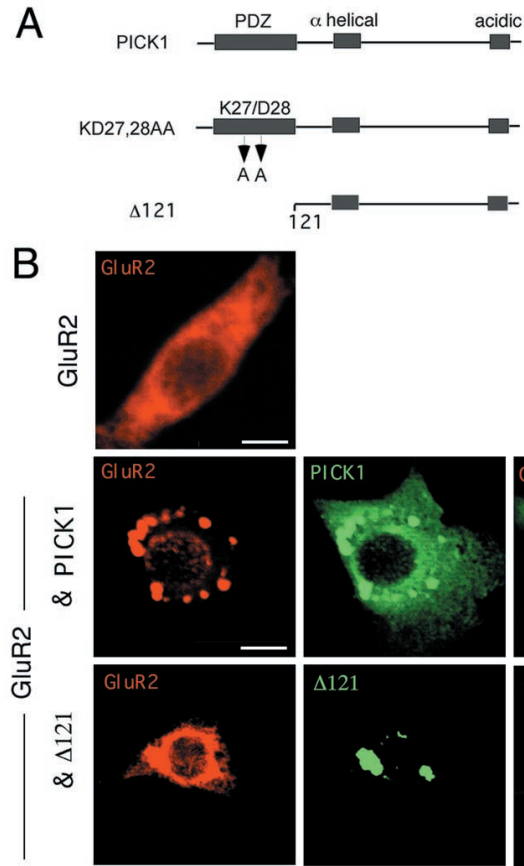

C

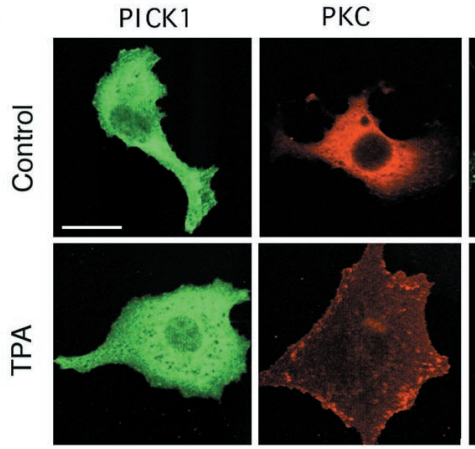

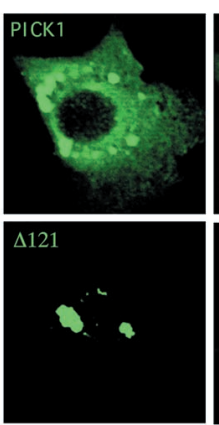

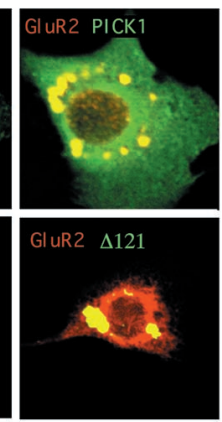

$\Delta 121$

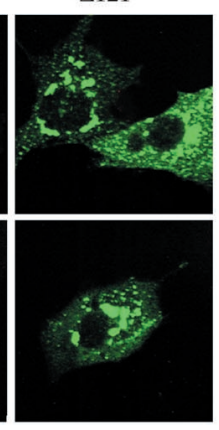

D
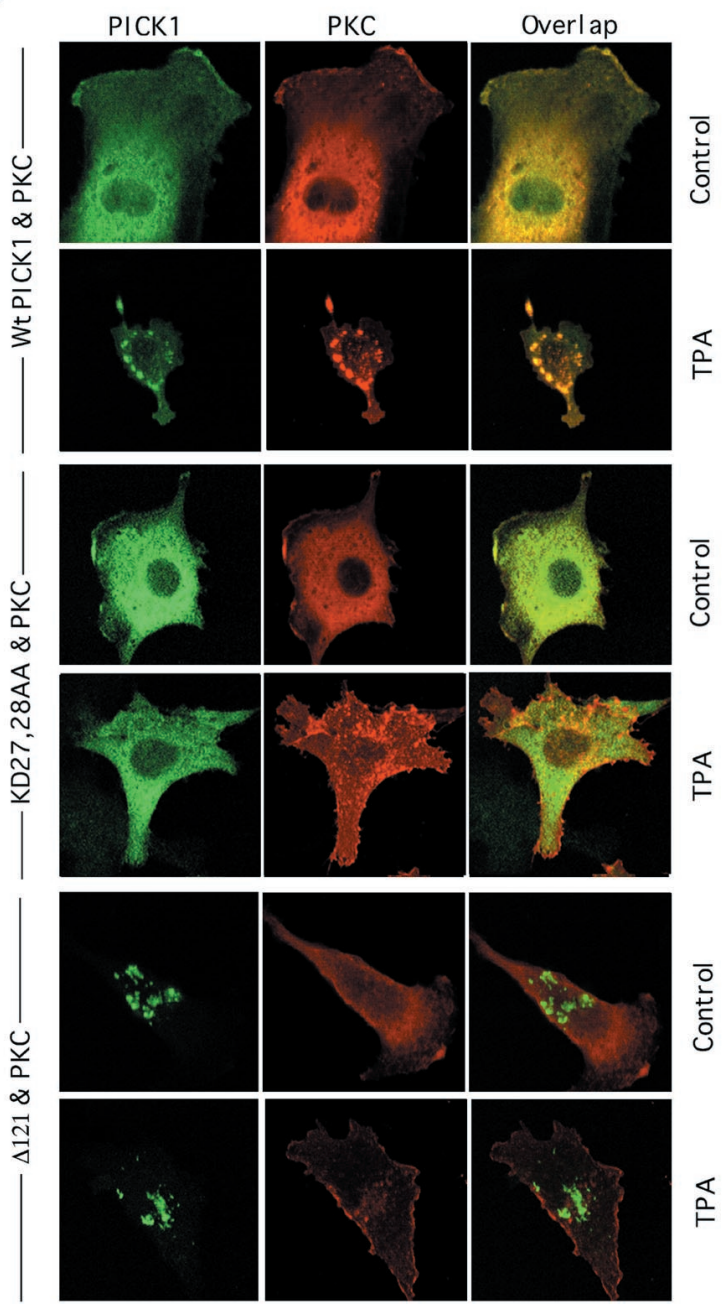

Figure 1. PICK1 forms perinuclear clusters after binding activated PKC $\alpha$ and GluR2, whereas the PICK1 mutant $\Delta 121$ forms clusters constitutively in 3 T3 cells. $A$, Structure of PICK1 and PDZ mutants of PICK1. PICK1 has an N-terminal PDZ domain, an $\alpha$-helical coiled coil domain, and a C-terminal acidic domain. The structures of the PDZ mutant KD27,28AA, which does not bind peptide C termini, and mutant $\Delta 121$, which lacks the PDZ domain altogether, are shown. In some experiments PICK1 and its mutants were tagged with the FLAG epitope at the PICK1 C terminus, as noted. $B$, GluR2 was expressed individually or in combination with PICK1 or the PICK1 mutant $\Delta 121$ in $3 T 3$ cells. GluR2 on its own displayed a diffuse cytoplasmic pattern, whereas the coexpression of PICK1 induced GluR2-PICK1 complexes that entered perinuclear clusters. $\Delta 121$ formed perinuclear clusters in the presence of GluR2 without influencing GluR2 distribution. Scale bar, $25 \mu \mathrm{m}$. $C$, 3T3 cells were transfected singly with vectors expressing PICK1, PKC $\alpha$, or mutant $\Delta 121$, as indicated. Parallel cultures were treated with TPA or were left untreated. Cells were permeabilized and stained by immunocytochemistry for the designated protein, as described in Materials and Methods. PICK1 displayed diff use staining with or without TPA treatment, whereas PKC $\alpha$ moved to the cell perimeter. Mutant $\Delta 121$ was in perinuclear clusters, with or without TPA stimulation. Scale bar, $25 \mu$ m. $D, 3 T 3$ cells were cotransfected with vectors expressing either PICK1 or mutants KD27,28AA or $\Delta 121$ plus a vector expressing PKC $\alpha$, as noted. Parallel cultures were treated with TPA or were left untreated as a control. Protein localization was visualized by double-immunofluorescent staining, as described in Materials and Methods. TPA induced the movement of coexpressed PICK1 and PKC $\alpha$ from a diffuse distribution to perinuclear clusters. In cells expressing KD27,28AA and PKC $\alpha$, TPA affected only the localization of PKC $\alpha$, which moved to the cell perimeter. The mutant $\Delta 121$ was constitutively present in clusters around the nucleus, whereas PKC $\alpha$ in the same cell as $\Delta 121$ underwent a TPA-induced movement to the cell perimeter. These results demonstrate a TPA-dependent formation of PICK1-PKC $\alpha$ complexes that are targeted to the 3 T3 cell perinuclear region.

and PICK1 in 3T3 cells. When 3 T3 cells were treated with TPA in the absence of exogenous PICK1, PKC $\alpha$ moved from a diffuse distribution to strong concentration within a band at the cell periphery, consistent with its association in the active form with the plasma membrane (Fig. $1 C$ ). However, in cells coexpressing exogenous PICK1, a different outcome of TPA treatment was seen. TPA dramatically affected the localization of both PICK1 and PKC, which colocalized with each other after TPA treatment in perinuclear clusters that strongly resembled the clusters formed by GluR2-PICK1 complexes in these cells (Fig. 1D). This suggested that TPA induced the formation of complexes between
PKC and PICK1, leading to a protein subcellular redistribution similar to that of PICK1-GluR2 complexes.

To confirm that protein interaction was required for $\mathrm{PKC} \alpha$ redistribution with PICK1, we assayed the effects of expression of the carboxylate binding loop mutant of PICK1, KD27,28AA (Staudinger et al., 1997), and the PDZ truncation mutant of PICK1, $\Delta 121$ (Fig. $1 A$ ). Neither of these mutants has a functional PDZ domain, and neither can make PDZ-dependent associations with other proteins. Mutant KD27,28AA did not redistribute when it was coexpressed with $\mathrm{PKC} \alpha$ and the cells were treated with TPA. In such cells PKC $\alpha$ moved to the cell perimeter, as 
seen in cells that were transfected with PKC $\alpha$ alone (Fig. 1D). These results demonstrate that the TPA-dependent redistribution of PKC $\alpha$ and PICK1 to perinuclear clusters requires the interaction of PKC $\alpha$ with the PICK1 PDZ domain. In cells coexpressing mutant $\Delta 121$ and $\mathrm{PKC} \alpha, \Delta 121$ was in a perinuclear location with or without TPA treatment, and PKC $\alpha$ moved to the cell perimeter after TPA treatment rather than to the $\Delta 121$ clusters, which were near the nucleus (Fig. 1D). This demonstrated that PKC $\alpha$ colocalization with PICK1 in the perinuclear clusters requires the TPA-dependent binding of PKC $\alpha$ to the PICK1 PDZ domain rather than simply the presence of clusters of PICK1 in the same cell. After the coexpression of GluR2 with $\Delta 121, \Delta 121$ also entered clusters without affecting GluR2 distribution (Fig. 1B). It was striking that removal of the PDZ domain mimicked the clustering effect of binding of a ligand to the PDZ domain. This suggested that PICK1 bearing an unliganded PDZ domain did not cluster and that clustering could be induced either by PDZ interaction with a ligand or by PDZ truncation.

To confirm the interaction of PICK1 with PKC $\alpha$, we performed immune coprecipitation assays. We expressed PKC $\alpha$ by transfection in $293 \mathrm{~T}$ cells, both with and without the coexpression of PICK1 that was tagged at the C terminus with a FLAG epitope. Simple coexpression generated only a low level of the PICK1PKC $\alpha$ complex, but a strong complex was observed when the cells were treated with TPA to activate PKC $\alpha$ (Fig. $2 A$ ). The formation of this complex was dependent on PICK1. PICK1 coimmunoprecipitated with GluR2 expressed in 293 T cells (Fig. 2B). In contrast to PKC $\alpha$, the binding of PICK1 to GluR2 was constitutive and did not require TPA treatment. In a pulldown assay the interaction of ${ }^{35} \mathrm{~S}$-labeled PICK1 with GST-R2C, a GST fusion to the GluR2 C terminus, was disrupted by a mutation of residue -2 of the GluR2 C terminus, V881A, and was decreased by mutations at positions -1 and +1 , K882A and I883A, but not the mutation to Alanine of the neighboring residues at $-3, \mathrm{~S} 880 \mathrm{~A}$, or at -4 , E879A (Fig. 2C). We conclude that PICK1 forms complexes selectively with the activated form of PKC $\alpha$. With GluR2 the interaction is constitutive and is strongly dependent on the side chain of V881, which lies within the PDZ binding site of GluR2.

\section{Molecular basis for PICK1 PDZ domain interaction with class I and class II termini}

We next analyzed the molecular basis for the ability of PICK1 to bind to both GluR2 and PKC $\alpha$. This capacity was surprising because the termini of these two proteins, which constitute the PDZ binding site, differ significantly in their sequences. Specificity of PDZ binding is achieved in part via the interaction of the PDZ $\alpha \mathrm{B} 1$ residue with the -2 position residue of the peptide terminus (Doyle et al., 1996; Songyang et al., 1997). Class I PDZ domains have a histidine at the $\alpha \mathrm{B} 1$ position that hydrogen-bonds to the hydroxyl group of serine or threonine at the -2 position of the peptide terminus. Class II domains, which carry a hydrophobic residue at position $\alpha \mathrm{B} 1$, bind peptide termini with hydrophobic or aromatic side chains at the -2 position (Songyang et al., 1997). Because the PKC $\alpha$ C terminus has a serine at the -2 position, it is expected to interact with class I PDZ domains. GluR2, however, has a hydrophobic valine at -2 and binds to the class II PDZ domains of ABP (Srivastava et al., 1998). In this context, the finding that the PICK1 PDZ can bind to the $\mathrm{C}$ termini of both GluR2 (ESVKI-COOH) and PKC $\alpha$ (LQSAV$\mathrm{COOH}$ ) suggests that the PICK1 PDZ has both class I and class
II binding characteristics. The PICK1 PDZ domain nonetheless shows selectivity of binding in its failure to bind to the $\mathrm{C}$ termini of GluR1, GluR4, or the NMDA receptor NR2A subunit (data not shown). Sequence alignment revealed that the PICK1 PDZ $\alpha \mathrm{B} 1$ residue is lysine. Lysine is novel in that it contains a polar $\mathrm{NH}_{3}{ }^{+}$moiety at the end of a hydrophobic aliphatic chain. The specificity of lysine in the $\alpha \mathrm{B} 1$-peptide interaction has not been examined. We therefore analyzed the basis for the capacity of the PICK1 PDZ domain for dual specificity by molecular homology modeling.

We modeled the PICK1 PDZ-GluR2 and PICK1 PDZ-PKC $\alpha$ complexes via homology with the three-dimensional crystallographic structure of a complex of peptide with PDZ3 of PSD-95 (Doyle et al., 1996) by using the ICM-Homology method (Cardozo et al., 1995). In the optimal conformation the PICK1 $\alpha \mathrm{B} 1$ Lys and the GluR2 Val (-2) form a hydrophobic contact involving the Val methyl groups, as predicted for a class II interaction (Fig. 2E). Although this model still must be regarded as hypothetical, the model explains the disruption of binding by the V881A mutation (Fig. 2C), which removes the aliphatic methyl groups of valine in the -2 position of the GluR2 terminus. It also implicates lysine as a novel class II $\alpha \mathrm{B} 1$ interaction residue. In contrast, computed models of the PICK1 PDZ-PKC $\alpha$ complex suggest that $\alpha \mathrm{B} 1$ Lys does not interact with the bound $\mathrm{PKC} \alpha$ peptide, including the -2 residue (Ser; Fig. $2 D$ ). Although $\mathrm{PKC} \alpha$ Ser 670 is not excluded from the PICK1 PDZ binding groove, its hydroxyl group points away from the PDZ binding pocket. This is in strong contrast to the role of -2 Ser or Thr in class I interactions with PDZ3 of PSD95, for which a hydrogen bond between the PDZ $\alpha \mathrm{B} 1$ residue (His) and a hydroxyl group from Ser or Thr at the -2 peptide position stabilizes the interaction (Doyle et al., 1996). The PICK1 PDZ appears to be permissive of the -3 serine in GluR2, which is held by the -3 pocket in a cradle of loose nonspecific interactions. This may permit PICK1 to bind S880phosphorylated GluR2 (see below). However, the PICK1 PDZ is selective for -3 glutamine in $\mathrm{PKC} \alpha$, which makes one specific -3 pocket interaction: a hydrogen bond between the serine hydroxyl group from the second $\beta$-strand of PICK1 PDZ and the side chain carbonyl of glutamine. Thus, the model suggests a molecular basis for the unusual capacity of the PICK1 PDZ domain to recognize particular class I and class II types of peptide termini.

\section{Dimerization of PICK1 and formation of heterocomplexes}

Proteins with multiple peptide binding motifs may nucleate the formation of multiprotein complexes. PICK1 dimers, for which the formation has been demonstrated in yeast (Xia et al., 1999) but not yet in animal cells, could assemble novel complexes involving class I and class II ligands. To determine whether PICK1 forms dimers or higher multimers in animal cells, we expressed the PICK1 mutant $\Delta 121-\mathrm{Myc}$, which lacks the PDZ domain, together with FLAG-tagged PICK1 mutants (Fig. $3 A$ ) in $293 \mathrm{~T}$ cells. We isolated complexes containing $\Delta 121-$ FLAG by immunoprecipitation and assayed for the Myc-tagged species by Western blotting (Fig. 3B). $\Delta 121-$ Myc formed a complex with wild-type PICK1-FLAG, with KD27,28AA-FLAG, and with $\Delta 121-$ FLAG. This indicated that the PICK1-PICK1 interaction was PDZ-independent and that the interaction region lies outside the PDZ domain. Also $\Delta 121-$ FLAG and mutant $379 \Delta-$ FLAG, which lacks the C-terminal negatively charged PICK1 region, and KD27,28AA-FLAG all formed complexes with wild-type PICK1-Myc (Fig. 3C). Thus neither the C-terminal-charged re- 

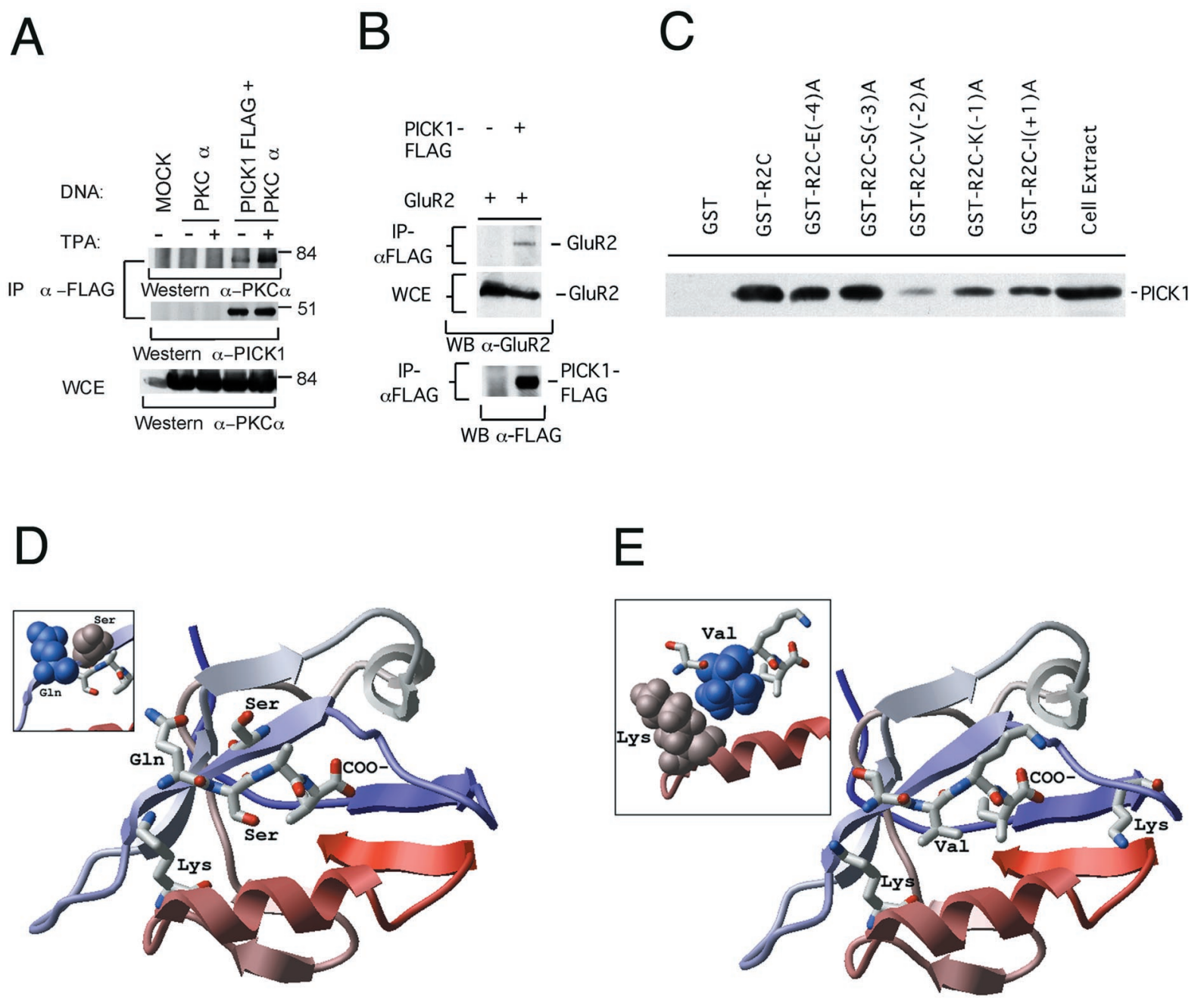

Figure 2. Immunoprecipitation of PICK1 complexes with activated PKC $\alpha$ and with GluR2 and molecular models of the complexes. $A$, $B$, The formation of complexes by PICK1 with PKC $\alpha$ and GluR2 was assayed in 293T cells. PICK1 formed complexes with PKC $\alpha$ exclusively in the PKC $\alpha$-activated form that was induced by TPA, but the formation of complexes with GluR2 was constitutive and depended strongly on V881 in the PDZ binding site of GluR2. $A$, 293T cells were transfected with plasmids expressing PKC $\alpha$ or PICK1-FLAG as shown or with an empty vector (MOCK). Parallel cultures were treated with TPA or were left untreated. Cell extracts were prepared, and complexes containing PICK1-FLAG were immunoprecipitated with anti-FLAG antibody and assayed for PKC $\alpha$ and PICK1 content by Western blot analysis with anti-PKC $\alpha$ and anti-PICK1 antibodies, respectively. The whole-cell extract (WCE) was Western blotted directly with anti-PKC $\alpha$ to confirm PKC $\alpha$ expression. TPA induced the formation of a complex of PKC $\alpha$ with PICK1. B, PICK1 protein tagged at its C terminus with the FLAG epitope was coexpressed in 293T cells with the GluR2 protein. Complexes containing PICK1 were isolated from detergent extracts by precipitation with anti-FLAG antibody and assayed for GluR2 by Western blot analysis with C-terminal $\alpha$-GluR2 antibody. The presence of GluR2 in whole-cell extracts (WCE) and PICK1 in anti-FLAG immunoprecipitates was confirmed by Western blotting. $C$, PICK1 protein expressed by in vitro translation in reticulocyte lysate and labeled with $\left[{ }^{35}\right.$ S $]$ methionine was incubated with wild-type and mutant GST-R2C, GluR2 C-terminus fusion proteins with the indicated Alanine substitution mutations; protein binding was assayed by gel electrophoresis and autoradiography. An aliquot of the translation extract was coelectrophoresed as a migration control. Mutations of three C-terminal amino acids to Alanine decreased PICK1 binding. D, E, PICK1 PDZ-PKC $\alpha$ and PICK1 PDZ-GluR2 complexes were modeled via homology with the three-dimensional crystallographic structure of a complex of peptide with PDZ3 of PSD-95 (Doyle et al., 1996) by the ICM-Homology method (Cardozo et al., 1995). Residues beyond the fourth amino acid of the sixth $\beta$-strand of PICK1 PDZ were truncated secondary to significant divergence from the parent structure. The side chains were placed optimally (Cardozo et al., 1995), and the model was refined together with the GluR2 C-terminal SV KI quadrapeptide or with the PKC $\alpha$ C-terminal QSAV quadrapeptide. The peptide backbone was tethered to occupy the same position as the backbone of the AQTSV peptide that was cocrystallized with PDZ3 of PSD-95, whereas the side chains of the peptide were optimized globally together with the surrounding PDZ side chains. D, A model of the PKC $\alpha$ C-terminal peptide QSAV bound to the PICK1 PDZ. Residue Q669 of PKC $\alpha$ can hydrogen-bond with a serine from the PICK1 PDZ $\beta$-strand. The inset represents a space-filling model of the interaction. Terminus-specific contacts are described in Results. $E$, A model of the PICK1 PDZ bound to the GluR2 C-terminal peptide SVKI. Residue V881 can form a hydrophobic contact with the $\alpha$ B1 lysine of PICK1 PDZ. The inset shows a space-filling model of this interaction.

gion nor the PDZ domain was required for interaction. However, $165 \Delta$-FLAG, which lacks a portion of the coiled coil domain and C-terminal neighboring sequences, and 135 $\Delta$-FLAG, which lacks all of the coiled coil domain, did not interact. We conclude that PICK1 dimerizes or multimerizes via the coiled coil region or the C-terminal neighboring sequences. Furthermore, the diffusely distributed form of PICK1 in 3T3 cells is dimeric (or multimeric). Thus the movement to perinuclear clusters induced by ligand binding is unlikely to reflect a PICK1 monomer-to-dimer transition.

We next asked whether a PICK1 dimer or higher multimer could form a heterocomplex in which it interacts simultaneously 
Figure 3. PICK1 dimers form via the coiled coil domain and can assemble heterocomplexes by interaction with the PKC $\alpha$ and GluR2 C termini. $A$, Diagrammatic structures of PICK and PICK1 PDZ truncation mutants. PICK1 peptides were tagged with a FLAG or a Myc epitope at the $\mathrm{C}$ terminus, as noted. $B$, The $\Delta 121-$ Myc mutant of the PICK1 peptide was coexpressed in 3T3 cells, with wild-type or mutant PICK1 tagged with a FLAG epitope, as noted. Complexes containing the FLAG-tagged species were isolated with anti-FLAG antibody and were analyzed for the $\Delta 121-$ Myc and the FLAG-tagged species by Western blotting. The expression of $\Delta 121-$ Myc was confirmed by Western blot analysis of the cell extracts. $C$, A series of FLAG-tagged mutants of PICK1, shown in $A$, was expressed in 3T3 cells together with PICK1-Myc, as noted. Complexes containing PICK1Myc were isolated with anti-Myc antibody and were assayed for FLAG-tagged PICK1 species by Western blotting. Blotting with anti-Myc antibody confirmed the presence of PICK1-Myc in these complexes. The expression of FLAGtagged PICK1 species was confirmed by Western blotting of the cell extracts with anti-FLAG antibody. $D$, The peptides PKC $\alpha$ and PICK1 and the PICK1 mutants KD27,28AA and $\Delta 121$ were expressed alone or in combination in $3 \mathrm{~T} 3$ cells; parallel cultures were treated with TPA or left untreated, as noted. Cell extracts were prepared and incubated with GST-R2C, a GST protein fusion to the C-terminal 50 amino acids of GluR2. Complexes containing GST-R2C were isolated on glutathione-Sepharose and were assayed for PICK1, PKC $\alpha$, and GST-R2C by Western blotting. Protein expression was confirmed by Western blot analysis. TPA induced the formation of a complex containing GST-R2C, PICK1, and PKC $\alpha$.

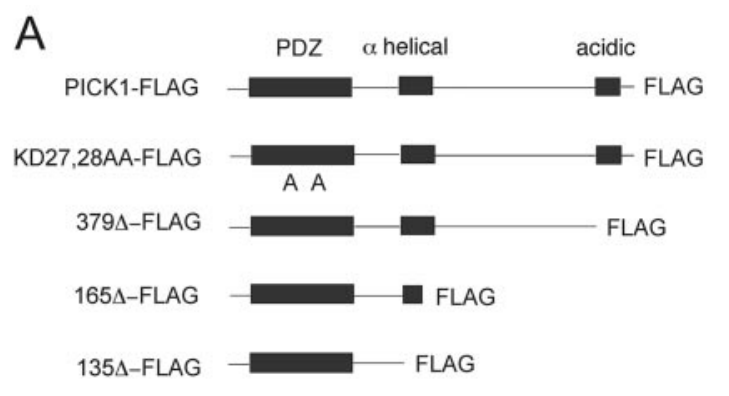

B

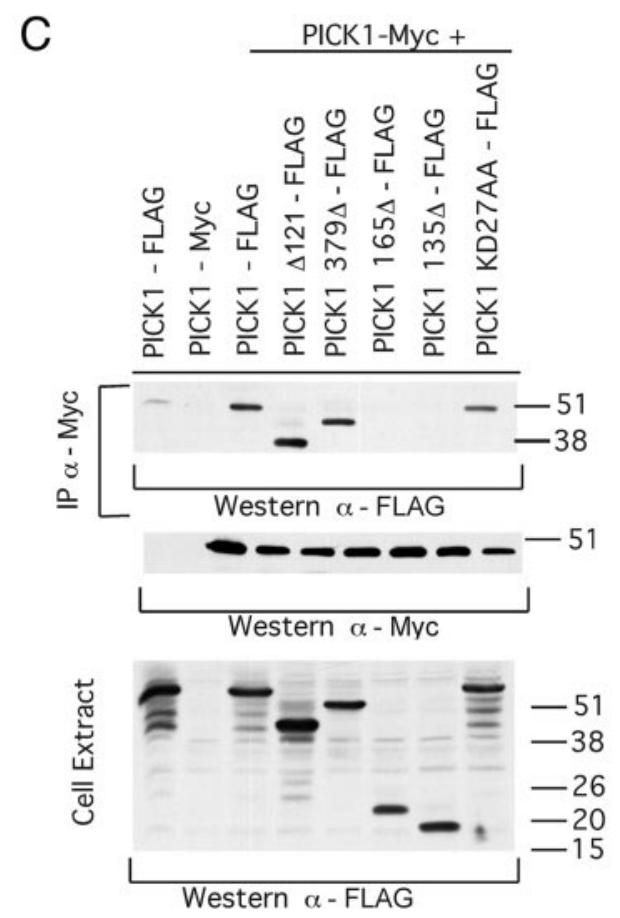

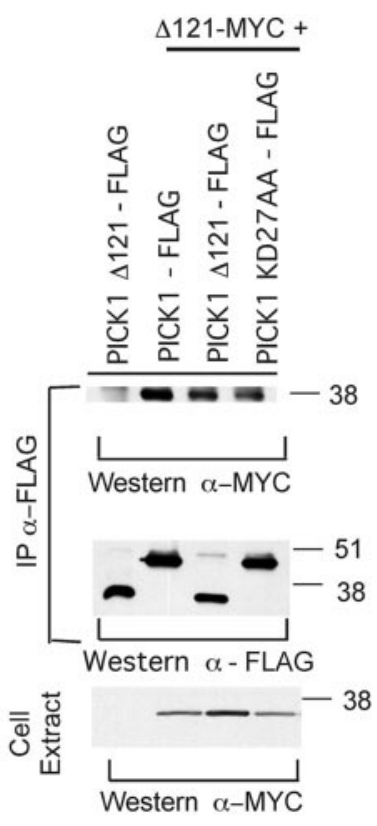
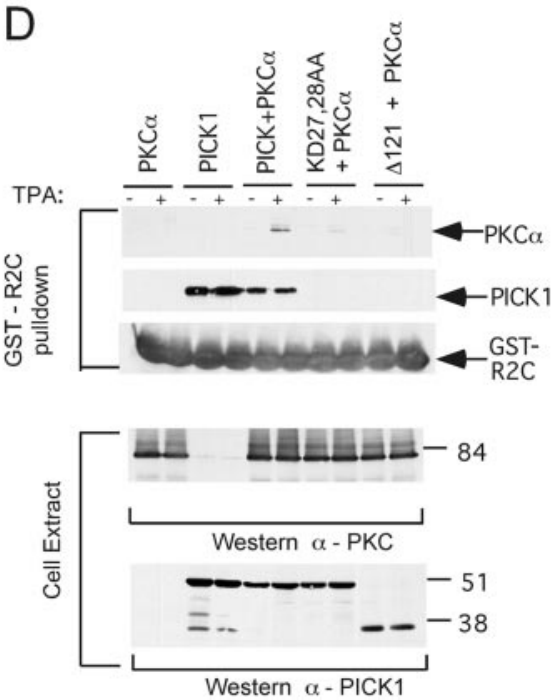

with the C termini of PKC $\alpha$ and GluR2. We coexpressed PKC $\alpha$ with PICK1, or $\Delta 121$ or KD27,28AA in $293 \mathrm{~T}$ cells with and without phorbol ester treatment. We incubated extracts from these cells with GST-R2C and Western-blotted the resulting complexes to detect the binding of PKC $\alpha$ (Fig. 3D). Extracts from TPA-treated, but not untreated, cells formed a complex containing $\mathrm{PKC} \alpha$ (lanes 5, 6). Formation of this complex was completely dependent on PICK1 (lanes 1, 2) and a functional PICK1 PDZ domain (lanes 7-10). This demonstrates that a heterocomplex, in which a PICK1 dimer or higher multimer is linked simultaneously to the $\mathrm{C}$ termini of PKC $\alpha$ and GluR2, forms by a phorbol ester and PDZ-dependent mechanism. Such a complex could target the activated form of PKC $\alpha$ to GluR2.

\section{PICK1 forms clusters with GluR2 in spines of hippocampal neurons}

The ability of PICK1 to redistribute GluR2 and PKC $\alpha$ in 3T3 cells suggested that PICK1 also might redistribute these proteins in neurons. To assay PICK1 properties in neurons, we expressed
PICK1 from Sindbis virus vectors in cultured primary embryonic hippocampal neurons at $18 \mathrm{~d}$ in vitro (18 DIV). Western blotting confirmed faithful protein expression from these viruses (Fig. $4 A$ ). Wild-type PICK1 protein expressed on its own was distributed throughout the neuron and penetrated into spines (Fig. 4B). To assay for PICK1 interaction with PKC in neurons, we expressed PICK1 from Sindbis, treated the cells with TPA to activate endogenous PKC, and observed PICK1 and PKC by immunofluorescence. Without TPA treatment PKC was distributed throughout the cell, including the dendritic shafts, and penetrated only weakly into spines (Fig. 4C). However, in TPAtreated cells PKC levels in spines were increased greatly, and PICK1 colocalized with PKC strongly in the spine clusters (Fig. $4 D)$. This suggested that with the activation of PKC, PICK1 forms complexes that redistribute PKC to spines, analogous to the perinuclear clustering of PKC complexes with PICK1 in 3T3 cells. For comparison, using Sindbis virus double infection, we coexpressed PICK1 in hippocampal neurons with MycGluR2, which is the GluR2 subunit tagged at the $\mathrm{N}$ terminus with a Myc epitope 

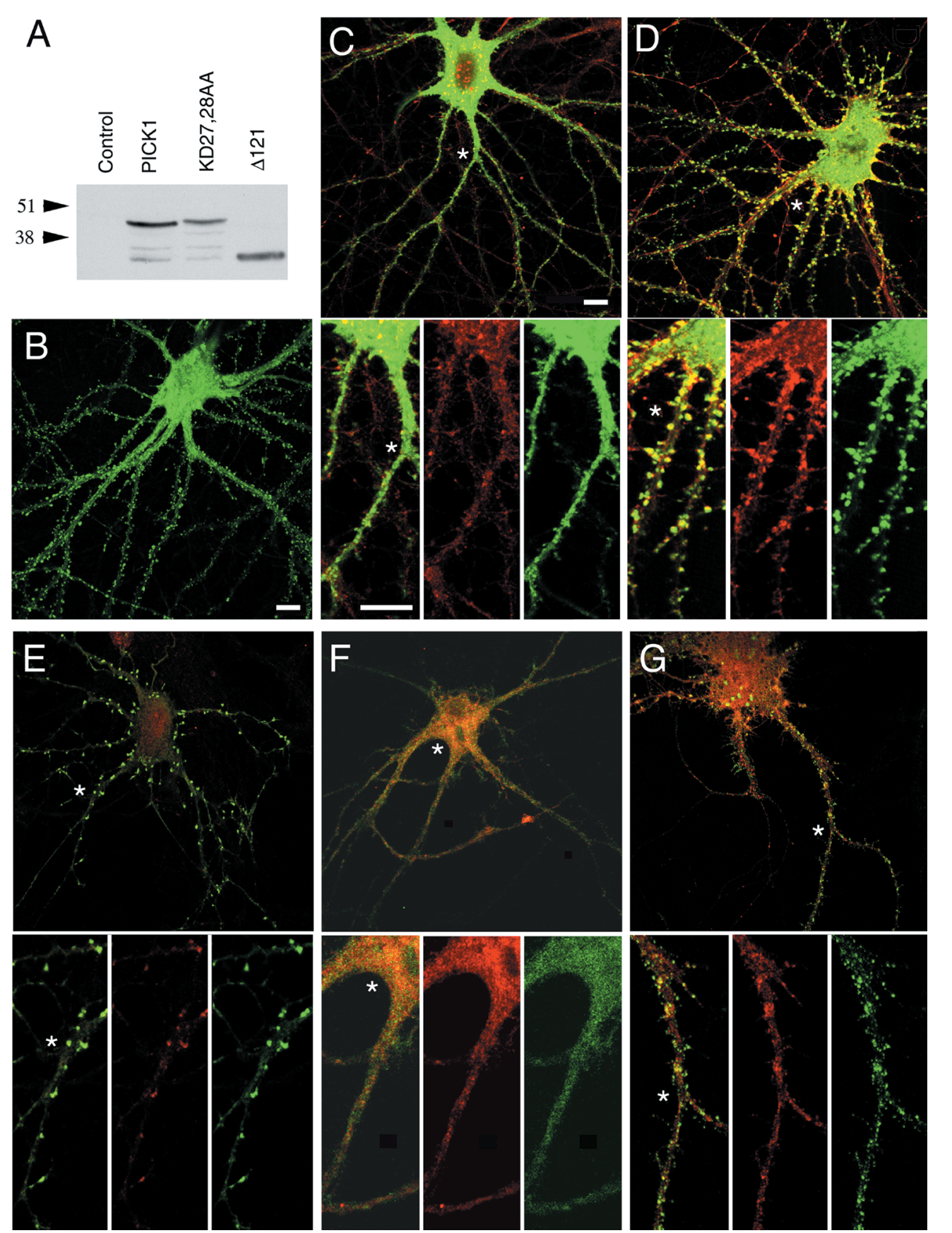

Figure 4. Interaction with PICK1 targets the activated form of $\mathrm{PKC} \alpha$ and GluR2 to spine clusters, whereas mutant $\Delta 121$ is targeted constitutively. PICK1, MycGluR2, and PICK1 or its mutants were expressed as noted in cultured embryonic hippocampal neurons 14 DIV from Sindbis virus vectors, and the virally encoded peptides were detected by immunofluorescence and confocal microscopy. A, Western blot analysis of extracts of cultured cortical neurons either uninfected (Control) or infected with Sindbis virus vectors expressing PICK1, KD27,28AA, or $\Delta 121$. Virally encoded PICK1 peptides were visualized by blotting with polyclonal anti-PICK1 serum. Peptide bands of the expected sizes confirm faithful peptide expression by the vectors. $B$, PICK1FLAG that is expressed on its own in hippocampal neurons is distributed diffusely in the cell body and enters spines. Scale bar, $10 \mu \mathrm{m}$. $C, D$, PICK1-FLAG was expressed from Sindbis virus in cultured hippocampal neurons; $24 \mathrm{hr}$ after infection the cells were treated with TPA $(D)$ or were left untreated as a control $(C)$. Immunofluorescent detection of endogenous PKC $\alpha$ with $\mathrm{PKC} \alpha$ antiserum (red) and of PICK1 with antiFLAG antibody (green) revealed that TPA induced the movement of PKC into spine clusters that contain PKC. The bottom three panels show higher magnification of the merged, the $\mathrm{PKC} \alpha$, and the PICK1 images, respectively. Asterisks in the top panels indicate the positions that have been magnified beneath. Scale bars (for both sets of panels), $10 \mu \mathrm{m}$. $E-G$, PICK1 $(E)$ or mutant KD27,28AA $(F)$ or mutant $\Delta 121(G)$ was coexpressed in hippocampal neurons with MycGluR2 by confection with two Sindbis virus vectors. Virally encoded peptides were visualized in permeabilized cells by indirect immunofluorescence and confocal microscopy. PICK1 and its mutants were detected via a FLAG epitope tag at the C terminus with anti-FLAG antiserum (green). MycGluR2 was visualized with anti-Myc polyclonal antiserum (red). PICK1 and MycGluR2 colocalized in spine clusters. When KD27,28AA was coexpressed with MycGluR2, both pep-

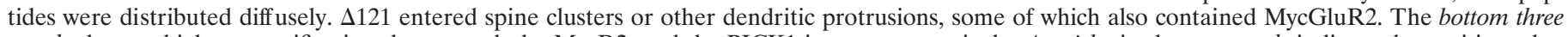

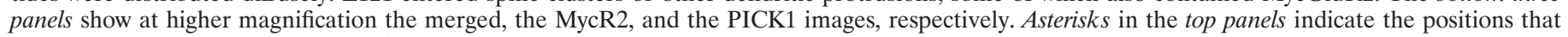
have been enlarged beneath. Magnification is as in $C$.

tag (Osten et al., 2000). As was seen with activated $\operatorname{PKC} \alpha$, coexpression of PICK1 with MycGluR2 caused a strong coclustering of the two proteins in spines (Fig. 4E). Mutant KD27,28AA failed to induce clustering (Fig. $4 F$ ), demonstrating that the high levels of MycGluR2 in spines seen in the presence of PICK1 required MycGluR2 interaction with the PICK1 PDZ domain. Strikingly, mutant $\Delta 121$ formed clusters in spiny protrusions, of which some colocalized with MycGluR2 and others did not (Fig. $4 G$ ). This resembled the perinuclear clustering of $\Delta 121$ in 3 T3 cells that was independent of GluR2. We conclude that PICK1 forms complexes with PKC and GluR2 that redistribute to spines. With PKC the formation of the complex and the redistri- bution to spines require kinase activation by TPA, as seen for complex formation in $3 \mathrm{~T} 3$ and $293 \mathrm{~T}$ cells. Because proteins in both complexes redistribute to spines, we also conclude that PICK1 induces the coclustering of GluR2 with the activated form of $\mathrm{PKC}$ in spines.

\section{TPA induces formation of intracellular spine clusters containing PICK1, PKC, and GluR2Ser880-PO}

Because clustering of PKC by PICK1 depends on PKC activation, PICK1 is highly likely to generate clusters that contain the activated form of PKC. We have shown that GluR2 enters similar clusters with PICK1. Because Ser880 of GluR2 is a substrate for 
Figure 5. Serine 880 phosphorylation of GluR2 in spine clusters with PICK1 and receptor endocytosis. $A$, Specificity of anti-GluR2Ser880-PO ${ }_{4}$ phosphopeptide antiserum. This serum recognizes GST-R2C phosphorylated in vitro by $\mathrm{PKC}$, but not untreated GST-R2C or GST-R2C S880A with or without TPA treatment. This establishes the specificity of the serum for GluR2Ser880-PO ${ }_{4}$ C-terminal sequences. $B$, Cultures of cortical neurons were treated with TPA or were left untreated. Immune precipitates of extracts with anti-GluR2Ser880-PO antiserum were analyzed by Western blotting with the same serum. TPA treatment strongly induced the formation of GluR2Ser880-PO ${ }_{4}$. C, Treatment of cultured hippocampal neurons with TPA induced the phosphorylation of endogenous GluR2 to yield GluR2Ser880-PO ${ }_{4}$. GluR2Ser880-PO was visualized by immunofluorescence with phosphopeptide antiserum and was abundant in spines. The signal was strongly competed by preincubation of the antibody with phosphopeptide antigen (data not shown). Scale bar, $20 \mu \mathrm{m}$. $D$, Cultured hippocampal neuron infected with Sindbis virus vector expressing PICK1-FLAG and treated with TPA. Shown are GluR2Ser880- $\mathrm{PO}_{4}$ phosphopeptide antiserum and rhodamineconjugated 20 antibody, and PICK1-FLAG with anti-FLAG antiserum and fluorescein-conjugated 20 antibody. PICK1 and GluR2Ser880- $\mathrm{PO}_{4}$ coclustered in spines. The panels on the right show color-resolved images of the region that has been indicated by an asterisk. Scale bar, $10 \mu \mathrm{m}$.
A
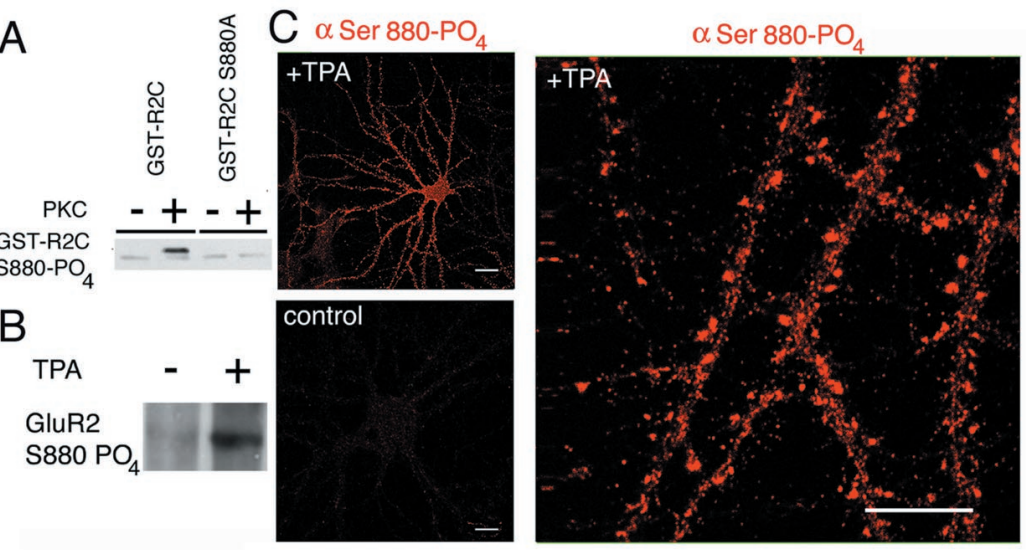

\section{D $\quad \alpha$ Ser 880-PO $/ \alpha F L A G$}

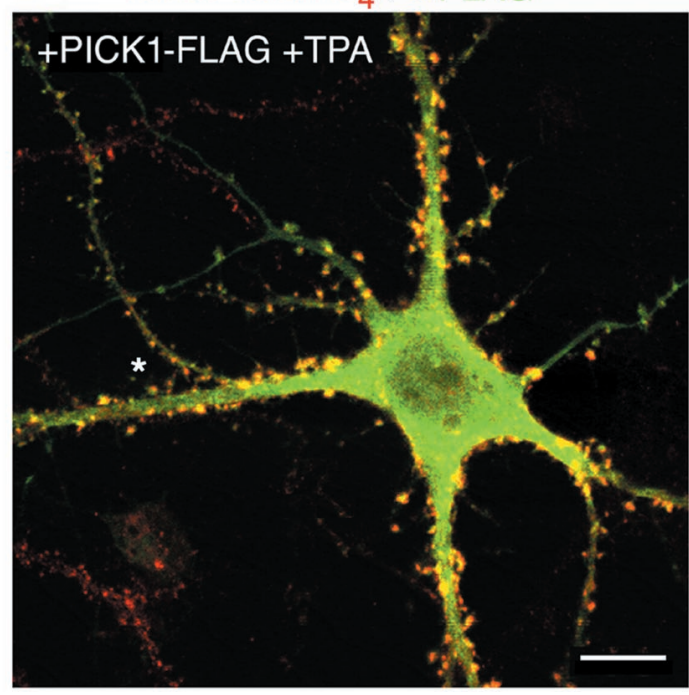

PKC (Matsuda et al., 1999, 2000; Chung et al., 2000), PICK1dependent clustering might promote the PKC phosphorylation of GluR2 by concentrating the kinase and the receptor subunit on a common membrane. This would result in the phosphorylation of GluR2 in the PICK1 clusters. To determine whether PICK1 clusters contain GluR2 that has been phosphorylated by PKC, we assayed the clusters for GluR2Ser880- $\mathrm{PO}_{4}$ by using an affinitypurified phosphopeptide antiserum. This serum recognized GSTR2C phosphorylated in vitro by PKC, but not untreated GST-R2C or GST-R2C S880A, either with or without exposure to PKC (Fig. 5A). In GST-R2C S880A the site of phosphorylation was mutated to Ala. Western blot analysis revealed that TPA induced a strong increase of GluR2Ser880- $\mathrm{PO}_{4}$ present in protein extracts from neurons, confirming the PKC phosphorylation of GluR2 in vivo (Fig. 5B). Immunofluorescence studies showed that GluR2Ser880- $\mathrm{PO}_{4}$ was abundant in dendrites of TPA-treated neurons, whereas in untreated controls the signal was absent or in some cells was confined primarily to the cell body (Fig. $5 C$; data not shown). The dendritic signal in TPA-treated cells was concentrated strongly in spines. In TPA-treated neurons expressing exogenous PICK1, GluR2Ser880-PO ${ }_{4}$ strongly colocalized with PICK1 in spines (Fig. 5D). Thus, GluR2Ser880- $\mathrm{PO}_{4}$ was induced by TPA and was abundant in the PICK1 clusters. This demonstrates that PICK1, PKC $\alpha$, and MycGluR2Ser880-PO ${ }_{4}$ all colocalize in spine clusters in TPA-treated cells. Phosphorylation of
GluR2 by PKC $\alpha$ thus could be promoted by PICK1-dependent colocalization of PKC $\alpha$ with GluR2.

\section{PICK1 reduces the synaptic levels of GluR2}

We analyzed further the spine clusters containing PICK1. PICK1 in spines colocalized with surface GluR1, a marker for AMPA receptor clusters, and with the synaptic marker SV2 (data not shown). To determine whether MycGluR2 in PICK1 clusters was intracellular or in the plasma membrane, we performed anti-Myc antibody surface staining of MycGluR2 in living neurons infected with two viruses expressing MycGluR2 and PICK1, respectively. Surface staining labels the extracellular Myc epitope tag of MycGluR2 (Osten et al., 2000). Although cells coexpressing the PICK mutant KD27,28AA and MycGluR2 showed high levels of surface expression of MycGluR2, cells coexpressing MycGluR2 and PICK1 had greatly diminished levels of surface MycGluR2 (Fig. 6A). This indicated that the PDZ-dependent association of MycGluR2 with wild-type PICK1 reduced the levels of MycGluR2 in the plasma membrane. We also analyzed the levels of surface and internal MycGluR2 in cells infected with Sindbis vectors encoding MycGluR2 and PICK1. Figure $6 B$ shows two neighboring cells. In one cell (marked by an asterisk), which is infected only by the virus expressing MycGluR2, MycGluR2 is prominent on the cell surface. In the other cell (marked by a double asterisk), which is infected by both viruses and is express- 
A

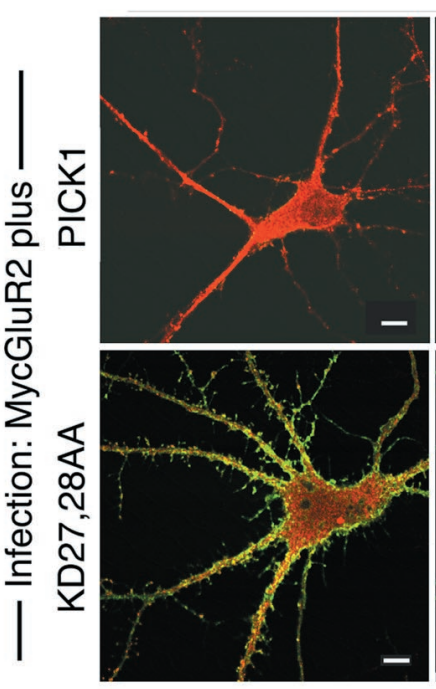

B
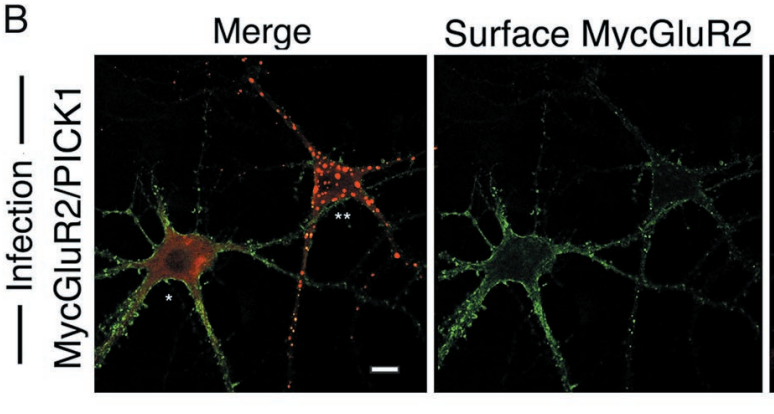

\section{Surface MycGluR2}

PICK1 (FLAG)

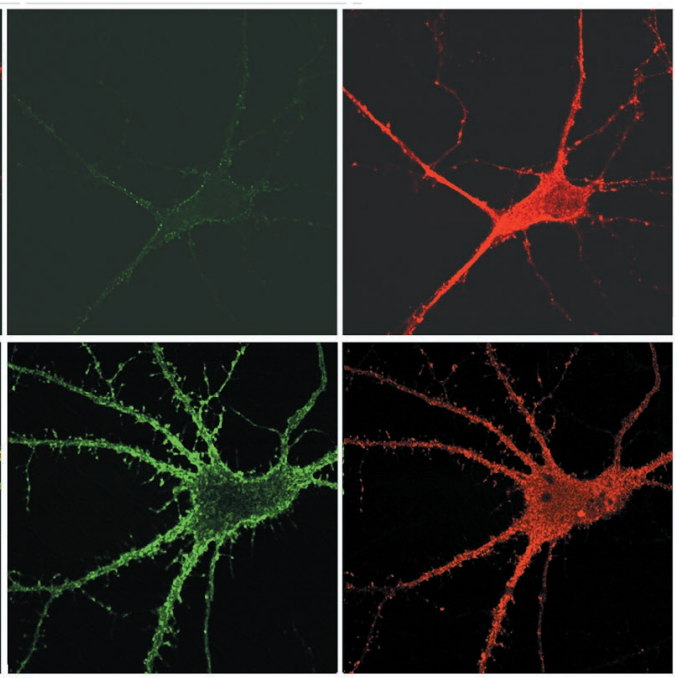

C

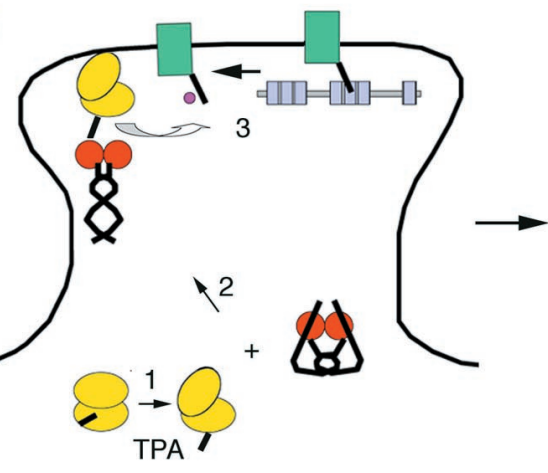

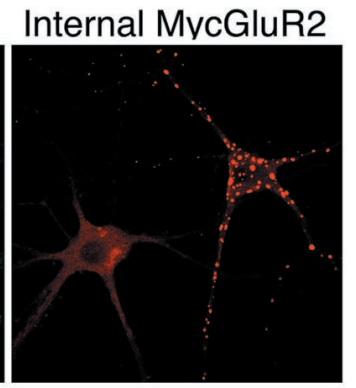

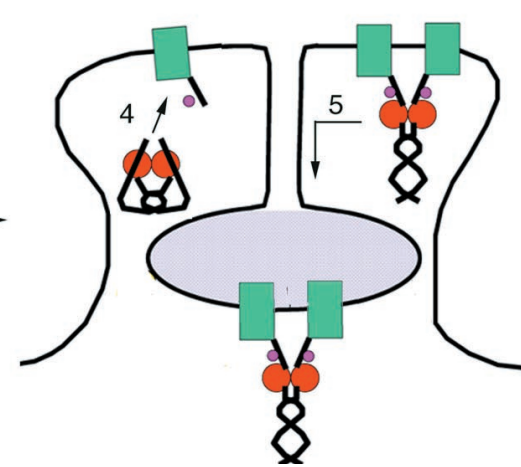

Figure 6. Reduction of plasma membrane levels of MycGluR2 by PICK1. $A$, Hippocampal neurons were coinfected with Sindbis virus vectors expressing MycGluR2 and PICK1 or MycGluR2 and KD27,28AA. Surface MycGluR2 was stained in living cells. Cells were permeabilized; PICK1 also was stained. Coexpression of MycGluR2 with PICK1, but not with KD27,28AA, reduced MycGluR2 surface levels. Scale bar, $10 \mu \mathrm{m}$. B, Hippocampal neurons were coinfected with Sindbis virus expressing MycGluR2 and PICK1. Cells were stained for surface and internal MycGluR2 as described previously (Osten et al., 2000). Shown is a pair of cells, one expressing only MycGluR2 and the other also expressing PICK1. *Cell infected with MycGluR2 expression Sindbis virus alone. ${ }^{* *}$ Cell infected with MycGluR2 expression Sindbis virus and with PICK1 expression Sindbis virus. The surface level of MycGluR2 is reduced greatly in the latter cell, but not in the former cell. Doubly infected cells were identified by the presence of characteristic MycGluR2 clusters. Scale bar, $10 \mu \mathrm{m}$. $C$, Model for the targeting of activated PKC $\alpha$ and PICK1 to spines and for the phosphorylation and endocytosis of GluR2. Activation of $\mathrm{PKC} \alpha$ (yellow) by TPA exposes the PDZ binding site at the $\mathrm{C}$ terminus of $\mathrm{PKC} \alpha$ (1). The PDZ binding site binds to a PDZ domain of a PICK1 dimer (red), inducing a structural transition in PICK1. The PICK1-PKC $\alpha$ complex is transported to spines (2). GluR2 (green) that is initially in a complex with ABP or GRIP ( gray) is released from this complex and is phosphorylated (purple circle) on serine 880 of the GluR2 C-terminal domain (3). The phosphorylated C terminus of GluR2 binds to PICK (4). The PICK1GluR2 complex is endocytosed (5). Not shown is the possible involvement of triple complexes in which PKC $\alpha$ and GluR2 are bound to the PDZ domains of a PICK1 dimer (see Discussion). GluR2 in this model is present in AMPA receptor complexes. ing both PICK1 and MycGluR2, the surface MycGluR2 signal is strongly reduced. Expression of PICK1 in the latter cell is demonstrated by the highly reproducible clustering of MycGluR2, which is characteristic of complexes of MycGluR2 with PICK1. Comparison of the internal MycGluR2 signals (Fig. 6B, right panel) in these two cells indicates that the intracellular levels of MycGluR2 in this latter PICK1-expressing cell are the same as those in the control cell lacking PICK1. We conclude that binding of a ligand, either GluR2 or activated PKC $\alpha$, to the PICK1 PDZ domain targets the resulting PICK1 complex to an intracellular location in spines and to clusters in dendritic shafts and soma and reduces MycGluR2 levels in the synaptic plasma membrane. The intracellular spine-targeting function of PICK1 is most likely provided by a motif in the non-PDZ region of the protein, because mutant $\Delta 121$ was found in clusters at spine-like sites. These findings are summarized in a model for the roles of PICK1 and PKC in the endocytosis of GluR2 (Fig. 6C).

\section{DISCUSSION}

We have analyzed the formation of complexes of PICK1 with PKC $\alpha$ and with GluR2. Formation of the PICK1-PKC $\alpha$ complexes is highly dependent on $\mathrm{PKC} \alpha$ activation, whereas the binding of GluR2 is constitutive. The redistribution of $\mathrm{PKC} \alpha$ PICK1 complexes to intracellular locations in spines is reminiscent of the targeting of activated CaMKII to the postsynaptic density and spines, where it binds to the NR1 and NR2A/B subunits of the NMDA receptor (Strack et al., 1997, 2000; Gardoni et al., 1998; Strack and Colbran, 1998; Leonard et al., 1999; Shen and Meyer, 1999). Our work suggests that peptide C-terminus interaction with the PICK1 PDZ triggers the redistribution. PKC $\alpha$ and PICK1 expressed individually are distributed widely in the cell and only cluster under conditions that enable the two to form a complex. In neurons expressing PKC $\alpha$ and PICK1, TPA activation of PKC induces coclusters containing 
PICK1, PKC $\alpha$, and the Ser880-PO 4 form of MycGluR2. Surface levels of MycGluR2 are strongly decreased in these cells. We suggest that phosphorylation promotes the accumulation of MycGluR2 in a form that is not bound to the anchor proteins ABP and GRIP and that is susceptible to PICK1-dependent transport from the synaptic membrane.

\section{Mechanism of PICK1 binding to PKC $\alpha$ and GluR2}

When phorbol esters and $\mathrm{Ca}^{2+}$ and/or phospholipids bind to the $\mathrm{PKC} \alpha$ regulatory domain, the kinase unfolds, disrupting an interaction of the catalytic domain with a pseudosubstrate inhibitory sequence. This conformational change may expose the PKC $\alpha$ C-terminal tail, allowing the tail to interact with the PICK1 PDZ domain. Dev et al. (2000) have demonstrated the formation of PKC $\alpha$-PICK1-mGluR7 complexes. Here we show that the formation of PICK1-PKC $\alpha$ complexes depends on PKC $\alpha$ activation. Similar to PICK1, a class of proteins known as RACKS, or receptors for activated $\mathrm{C}$ kinase, bind to activated $\mathrm{PKC}$ isoforms and regulate their kinase activity (Csukai et al., 1997). As with PICK1, these PKC binding proteins colocalize with selected PKC isozyme types after kinase activation (Csukai et al., 1997).

\section{PICK1 redirects the membrane location of the activated form of PKC}

When neurons or 3T3 cells were treated with TPA without exogenous PICK1 expression, PKC $\alpha$ moved from the cytoplasm to the plasma membrane, as reported previously (Kraft and Anderson, 1983; Shoji et al., 1986). However, PKC redistributed to perinuclear clusters in $3 \mathrm{~T} 3$ cells and to spine and dendritic clusters in neurons in the presence of exogenously expressed PICK1. This strongly suggests that PICK1 redirects the targeting of PKC $\alpha$ via formation of the PICK1-PKC $\alpha$ complexes. In this regard, it is striking that deletion of the PICK1 PDZ domain in mutant $\Delta 121$ PICK1 drove the truncated PICK1 into clusters similar to those seen for PICK1-PKC $\alpha$ and PICK1-GluR2 complexes. This suggests that a clustering or targeting motif lies within the region of PICK1 contained in $\Delta 121$. Either ligand binding to the PDZ domain or PDZ deletion may induce a PICK1 transition that unmasks this putative motif, directing PICK1 and its associated factors to the clusters. Preliminary efforts to colocalize the clusters with markers for intracellular compartments have not been successful, and further work will be required to determine their identity. Analysis of endogenous PICK1 awaits the generation of sensitive PICK1 reagents.

\section{Novel PDZ specificity and PICK1 formation of dimers}

Molecular modeling of the PICK1 PDZ domain suggests that the binding of PICK1 to PKC $\alpha$ depends on an interaction between the $\beta \mathrm{B} 2$ serine of the PICK1 PDZ and the -3 glutamine of $\mathrm{PKC} \alpha$. This is in contrast to the more common class I $\alpha \mathrm{B} 1$ histidine interaction with Ser or Thr at the C-terminus -2 position of the peptide terminus (Doyle et al., 1996; Songyang et al., 1997). Indeed the modeling, although still hypothetical, indicates that the hydroxyl group of Ser at the -2 position of PKC $\alpha$ (Ser 690) points away from the PDZ domain, perhaps enabling PICK1 to bind when this serine is phosphorylated. When PICK1 binds to GluR2, the carbenes of the $\alpha \mathrm{B} 1$ lysine as well as the $\beta \mathrm{B} 3$ isoleucine and the $\alpha \mathrm{B} 5$ alanine all make hydrophobic interactions with the -2 valine of GluR2, characteristic of a class II interaction. Indeed, mutation of the GluR2 -2 valine to alanine strongly reduced binding to PICK1. Thus it appears that PICK1 binds to $\mathrm{PKC} \alpha$ via a novel set of interactions rather than a conventional class I interaction and to GluR2 via a variation of the class II interaction involving Lys at position -2 of GluR2. Confirmation of this model will require further studies of the effects of PDZ domain and $\mathrm{C}$-terminus mutation.

The novel specificity indicated by the model could enable PICK1 to engage both GluR2 and PKC $\alpha$ and to target them to a common membrane location, facilitating PKC phosphorylation of GluR2. This is particularly significant in view of our demonstration that PICK1 forms dimers or higher multimers that are stabilized by coiled coil domain interactions. Proteins with multiple PDZ domains can nucleate the formation of multi-protein complexes. INAD, a component of the rhabdomere of Drosophila photoreceptor cells, organizes multiple signal-transducing proteins including PLC and PKC $\alpha$ at the cell membrane by virtue of its multiple PDZ domains (Huber et al., 1996a,b; Chevesich et al., 1997). PICK1 multimers may assemble heterocomplexes with GluR2 and PKC $\alpha$. We have demonstrated the assembly of a GST-R2C-PICK1/PICK1-PKC $\alpha$ complex, dependent on TPA. The dependence on TPA indicates that the complex contains the activated form of PKC $\alpha$. The complex may be similar to the PKC $\alpha$, PICK1, mGluR7 complex reported by Dev et al. (2000) in COS cells.

\section{Model for regulated endocytosis mediated by PICK1}

Figure $6 C$ presents a model for PICK1 action in PKC $\alpha$-induced GluR2 endocytosis. In this model, PKC $\alpha$ is initially in its inactive form. However, with PKC $\alpha$ activation the PDZ binding site at the PKC $\alpha \mathrm{C}$ terminus is exposed and binds to a PDZ domain of a PICK1 dimer. PICK1 then undergoes a structural transition that is associated with an intracellular redistribution of PICK1 from diffuse in the cytoplasm to clustered at spine and intradendritic membranes. As a consequence of this redistribution, $\mathrm{PKC} \alpha$ is localized at the spine plasma membrane where it can phosphorylate the $\mathrm{C}$ terminus of GluR2. It is not known whether the GluR2 C terminus can be phosphorylated while it is in a complex with ABP or GRIP. Indeed, Dev et al. have reported that the binding of mGluR7 to the PICK1 PDZ domain hinders its phosphorylation by PKC $\alpha$ (Dev et al., 2000). For the GluR2 C terminus to be phosphorylated by PKC $\alpha$, it may be necessary for it first to release from ABP or GRIP. Little is known about the mechanisms of PDZ release, but this step could be regulated and could determine the availability of GluR2 for phosphorylation. Because the phosphorylation of S880 of GluR2 by PKC $\alpha$ prevents GluR2 binding to GRIP (Matsuda et al., 1999, 2000; Chung et al., 2000), such phosphorylation could make persistent a dissociation of GluR2 from ABP and GRIP. Because S880 phosphorylation of GluR2 is compatible with GluR2 binding to PICK1 (Chung et al., 2000), GluR2 released from a synaptic anchor and phosphorylated by PKC $\alpha$ could accumulate in PICK1 complexes, inducing a PICK1 structural transition and redistribution of PICK1-GluR2 complexes to internal membranes. This in turn would reduce synaptic levels of the receptor. Long-term depression (LTD)-, ligand-, and insulin-induced endocytosis of AMPA receptors takes place by clathrin- and dynamin-dependent mechanisms (Carroll et al., 1999; Man et al., 2000). The role of clathrin in the PICK1-dependent reduction of the surface GluR2 described here is not yet known.

Cerebellar LTD is induced by the activation of PKC and involves postsynaptic AMPA receptor downregulation at the Purkinje cell-parallel fiber synapses (Wang and Linden, 2000; Xia et al., 2000). A substantial proportion of AMPA receptors at these synapses is composed of GluR2 plus GluR3 subunits (Z hao 
et al., 1998). Because GluR3 also binds PICK1, AMPA receptors at parallel fiber-Purkinje cells synapses may be trafficked similarly to the MycGluR2 channels studied here. Indeed, by using patch pipette perfusion of peptides to disrupt GluR2/3 C-terminal peptide interactions in Purkinje cells, Xia et al. (2000) found evidence for a PICK1-dependent step in cerebellar LTD. These workers also used dominant-negative PICK1-GST fusion proteins to demonstrate a dependence of LTD on putative PICK1 dimerization. Daw et al. (2000) have proposed, on the basis of peptide perfusion studies, that GluR2 PDZ interactions retain AMPA receptors in intracellular stores and that phosphorylation by $\mathrm{PKC} \alpha$ releases these receptors for insertion into the synaptic membrane. These observations are compatible with the present work and suggest that phosphorylation by PKC may have a more general role, triggering the movement of AMPA receptors into the plasma membrane as well as removing them.

Because a number of other membrane proteins besides GluR2 also bind to PICK1, the mechanisms described here may contribute more generally to regulated protein subcellular relocalization. We also note that GluR1 interacts with a different set of plasma membrane anchors from GluR2 and obeys different trafficking properties from GluR2 (Leonard et al., 1998; Hayashi et al., 2000). The effects of GluR1 subunits on PICK1 relocalization of heteromeric AMPA receptors remain to be determined.

\section{REFERENCES}

Boudin H, Doan A, Xia J, Shigemoto R, Huganir RL, Worley P, Craig AM (2000) Presynaptic clustering of mGluR7a requires the PICK1 PDZ domain binding site. Neuron 28:485-497.

Burette A, Khatri L, Wyszynski M, Sheng M, Weinberg RJ, Ziff EB (2001) Differential cellular and subcellular localization of the AMPA receptor-binding protein and glutamate receptor-interacting protein. J Neurosci 21:495-503.

Cardozo T, Totrov M, Abagyan R (1995) Homology modeling by the ICM method. Proteins 23:403-414.

Carroll RC, Beattie EC, Xia H, Luscher C, Altschuler Y, Nicoll RA, Malenka RC, von Zastrow M (1999) Dynamin-dependent endocytosis of ionotropic glutamate receptors. Proc Natl Acad Sci USA 96:14112-14117.

Chevesich J, Kreuz AJ, Montell C (1997) Requirement for the PDZ domain protein, INAD, for localization of the TRP store-operated channel to a signaling complex. Neuron 18:95-105.

Chung HJ, Xia J, Scannevin RH, Zhang X, Huganir RL (2000) Phosphorylation of the AMPA receptor subunit GluR2 differentially regulates its interaction with PDZ domain-containing proteins. J Neurosci 20:7258-7267.

Csukai M, Chen CH, De Matteis MA, Mochly-Rosen D (1997) The coatomer protein $\beta^{\prime}-\mathrm{COP}$, a selective binding protein (RACK) for protein kinase C $\epsilon$. J Biol Chem 272:29200-29206.

Daw MI, Chittajallu R, Bortolotto ZA, Dev KK, Duprat F, Henley JM, Collingridge GL, Isaac JT (2000) PDZ proteins interacting with C-terminal GluR2/3 are involved in a PKC-dependent regulation of AMPA receptors at hippocampal synapses. Neuron 28:873-886.

Dev KK, Nishimune A, Henley JM, Nakanishi S (1999) The protein kinase $\mathrm{C} \alpha$ binding protein PICK1 interacts with short but not long form alternative splice variants of AMPA receptor subunits. Neuropharmacology 38:635-644.

Dev KK, Nakajima Y, Kitano J, Braithwaite SP, Henley JM, Nakanishi S (2000) PICK1 interacts with and regulates PKC phosphorylation of mGLUR7. J Neurosci 20:7252-7257.

Dong H, O'Brien RJ, Fung ET, Lanahan AA, Worley PF, Huganir RL (1997) GRIP: a synaptic PDZ domain-containing protein that interacts with AMPA receptors. Nature 386:279-284.

Doyle DA, Lee A, Lewis J, Kim E, Sheng M, MacKinnon R (1996) Crystal structures of a complexed and peptide-free membrane proteinbinding domain: molecular basis of peptide recognition by PDZ. Cell 85:1067-1076.

El Far O, Airas J, Wischmeyer E, Nehring RB, Karschin A, Betz H (2000) Interaction of the C-terminal tail region of the metabotropic glutamate receptor 7 with the protein kinase C substrate PICK1. Eur J Neurosci 12:4215-4221.
Gardoni F, Caputi A, Cimino M, Pastorino L, Cattabeni F, Di Luca M (1998) Calcium/calmodulin-dependent protein kinase II is associated with NR2A/B subunits of NMDA receptor in postsynaptic densities. J Neurochem 71:1733-1741.

Hayashi Y, Shi SH, Esteban JA, Piccini A, Poncer JC, Malinow R (2000) Driving AMPA receptors into synapses by LTP and CaMKII: requirement for GluR1 and PDZ domain interaction. Science 287:2262-2267.

Hollmann M, Heinemann S (1994) Cloned glutamate receptors. Annu Rev Neurosci 17:31-108.

Huber A, Sander P, Paulsen R (1996a) Phosphorylation of the InaD gene product, a photoreceptor membrane protein required for recovery of visual excitation. J Biol Chem 271:11710-11717.

Huber A, Sander P, Gobert A, Bahner M, Hermann R, Paulsen R (1996b) The transient receptor potential protein (Trp), a putative store-operated $\mathrm{Ca}^{2+}$ channel essential for phosphoinositide-mediated photoreception, forms a signaling complex with NorpA, InaC, and InaD. EMBO J 15:7036-7045.

Kraft AS, Anderson WB (1983) Phorbol esters increase the amount of $\mathrm{Ca}^{2+}$, phospholipid-dependent protein kinase associated with plasma membrane. Nature 301:621-623.

Leonard AS, Davare MA, Horne MC, Garner CC, Hell JW (1998) SAP97 is associated with the $\alpha$-amino-3-hydroxy-5-methylisoxazole4-propionic acid receptor GluR1 subunit. J Biol Chem 273:19518-19524.

Leonard AS, Lim IA, Hemsworth DE, Horne MC, Hell JW (1999) Calcium/calmodulin-dependent protein kinase II is associated with the $N$-methyl-D-aspartate receptor. Proc Natl Acad Sci USA 96:3239-3244.

Luscher C, Nicoll RA, Malenka RC, Muller D (2000) Synaptic plasticity and dynamic modulation of the postsynaptic membrane. Nat Neurosci 3:545-550.

Malinow R, Mainen ZF, Hayashi Y (2000) LTP mechanisms: from silence to four-lane traffic. Curr Opin Neurobiol 10:352-357.

Man YH, Lin JW, Ju WH, Ahmadian G, Liu L, Becker LE, Sheng M, Wang YT (2000) Regulation of AMPA receptor-mediated synaptic transmission by clathrin-dependent receptor internalization. Neuron 25:649-662.

Matsuda S, Mikawa S, Hirai H (1999) Phosphorylation of serine-880 in GluR2 by protein kinase $\mathrm{C}$ prevents its $\mathrm{C}$ terminus from binding with glutamate receptor-interacting protein. J Neurochem 73:1765-1768.

Matsuda S, Launey T, Mikawa S, Hirai H (2000) Disruption of AMPA receptor GluR2 clusters following long-term depression induction in cerebellar Purkinje neurons. EMBO J 19:2765-2774.

Newton AC (1997) Regulation of protein kinase C. Curr Opin Cell Biol 9:161-167.

Orr JW, Keranen LM, Newton AC (1992) Reversible exposure of the pseudosubstrate domain of protein kinase $\mathrm{C}$ by phosphatidylserine and diacylglycerol. J Biol Chem 267:15263-15266.

Osten P, Srivastava S, Inman GJ, Vilim FS, Khatri L, Lee LM, States BA, Einheber S, Milner TA, Hanson PI, Ziff EB (1998) The AMPA receptor GluR2 C terminus can mediate a reversible, ATP-dependent interaction with NSF and $\alpha$ - and $\beta$-SNAPs. Neuron 21:99-110.

Osten P, Khatri L, Perez JL, Kohr G, Giese G, Daly C, Schulz TW, Wensky A, Lee LM, Ziff EB (2000) Mutagenesis reveals a role for ABP/GRIP binding to GluR2 in synaptic surface accumulation of the AMPA receptor. Neuron 27:313-325.

Seeburg PH (1993) The Trends in Neuroscience/TiPS lecture. The molecular biology of mammalian glutamate receptor channels. Trends Neurosci 16:359-365.

Shen K, Meyer T (1999) Dynamic control of CaMKII translocation and localization in hippocampal neurons by NMDA receptor stimulation. Science 284:162-166.

Shoji M, Girard PR, Mazzei GJ, Vogler WR, Kuo JF (1986) Immunocytochemical evidence for phorbol ester-induced protein kinase $\mathrm{C}$ translocation in HL60 cells. Biochem Biophys Res Commun 135:1144-1149.

Songyang Z, Fanning AS, Fu C, Xu J, Marfatia SM, Chishti AH, Crompton A, Chan AC, Anderson JM, Cantley LC (1997) Recognition of unique carboxyl-terminal motifs by distinct PDZ domains. Science 275:73-77.

Srivastava S, Osten P, Vilim FS, Khatri L, Inman G, States B, Daly C, DeSouza S, Abagyan R, Valtschanoff JG, Weinberg RJ, Ziff EB (1998) Novel anchorage of GluR2/3 to the postsynaptic density by the AMPA receptor-binding protein ABP. Neuron 21:581-591.

Staudinger J, Zhou J, Burgess R, Elledge SJ, Olson EN (1995) PICK1: a perinuclear binding protein and substrate for protein kinase $\mathrm{C}$ isolated by the yeast two-hybrid system. J Cell Biol 128:263-271.

Staudinger J, Lu J, Olson EN (1997) Specific interaction of the PDZ domain protein PICK1 with the $\mathrm{COOH}$ terminus of protein kinase C- $\alpha$. J Biol Chem 272:32019-32024.

Strack S, Colbran RJ (1998) Autophosphorylation-dependent targeting of calcium/calmodulin-dependent protein kinase II by the NR2B subunit of the $N$-methyl-D-aspartate receptor. J Biol Chem 273:20689-20692. 
Strack S, Choi S, Lovinger DM, Colbran RJ (1997) Translocation of autophosphorylated calcium/calmodulin-dependent protein kinase II to the postsynaptic density. J Biol Chem 272:13467-13470.

Strack S, McNeill RB, Colbran RJ (2000) Mechanism and regulation of calcium/calmodulin-dependent protein kinase II targeting to the NR2B subunit of the $N$-methyl-D-aspartate receptor. J Biol Chem 275:23798-23806.

Takeya R, Takeshige K, Sumimoto H (2000) Interaction of the PDZ domain of human PICK1 with class I ADP-ribosylation factors. Biochem Biophys Res Commun 267:149-155.

Torres R, Firestein BL, Dong H, Staudinger J, Olson EN, Huganir RL, Bredt DS, Gale NW, Yancopoulos GD (1998) PDZ proteins bind, cluster, and synaptically colocalize with Eph receptors and their ephrin ligands. Neuron 21:1453-1463.
Wang YT, Linden DJ (2000) Expression of cerebellar long-term depression requires postsynaptic clathrin-mediated endocytosis. Neuron $25: 635-647$.

Xia J, Zhang X, Staudinger J, Huganir RL (1999) Clustering of AMPA receptors by the synaptic PDZ domain-containing protein PICK1. Neuron 22:179-187.

Xia J, Chung HJ, Wihler C, Huganir RL, Linden DJ (2000) Cerebellar long-term depression requires $\mathrm{PKC}$-regulated interactions between GluR2/3 and PDZ domain-containing proteins. Neuron 28:499-510.

Zhao HM, Wenthold RJ, Petralia RS (1998) Glutamate receptor targeting to synaptic populations on Purkinje cells is developmentally regulated. J Neurosci 18:5517-5528.

Ziff EB (1997) Enlightening the postsynaptic density. Neuron 19:11631174. 